\title{
Experimental Study on Brush-Painted Passive RFID-Based Humidity Sensors Embedded into Plywood Structures
}

\author{
Erja Sipilä, Johanna Virkki, Lauri Sydänheimo, and Leena Ukkonen \\ Department of Electronics and Communications Engineering, Tampere University of Technology, P.O. Box 692, 33101 Tampere, Finland \\ Correspondence should be addressed to Erja Sipilä; erja.sipila@tut.fi
}

Received 18 November 2015; Accepted 22 December 2015

Academic Editor: Jaume Anguera

Copyright (C) 2016 Erja Sipilä et al. This is an open access article distributed under the Creative Commons Attribution License, which permits unrestricted use, distribution, and reproduction in any medium, provided the original work is properly cited.

\begin{abstract}
The integration of electronics and wood is an interesting research area due to the increasing interest to add functionality into various wooden products. The passive RFID-based humidity sensor tag prototype, presented in this paper, is fabricated directly on plywood substrate to be embedded into wooden structures, by using brush-painting and photonic sintering of cost-effective silver ink. To the best of our knowledge, this is the first demonstration of brush-painted antennas as sensor elements. The developed sensor tag is fully passive and small in size, meaning it can be permanently enclosed into wooden structures. In addition, the sensor tag has all the functionalities of an ordinary passive UHF RFID tag, and a peak read range of about 10 meters. The sensor performance was evaluated in normal room conditions, after two 100\% relative humidity tests, and after drying in normal room conditions for 9 days. According to the results, the fabricated UHF RFID-based humidity sensor tags have a great potential to be utilized in humidity sensing applications, and also in normal automatic identification and supply chain control of various wooden products. In addition, the first results of more cost-effective brush-painted copper UHF RFID tags on plywood substrate are presented.
\end{abstract}

\section{Introduction}

Embedding of electronics as a part of versatile structures is a growing trend, especially along the emerging paradigm of the Internet of Things (IoT) [1]. Many industries are interested in novel smart products with identification and sensing possibilities. In addition to logistics and supply chain control, great potential lies especially in the construction, packaging, and furniture industries, where wood is a typical material. This makes the integration of electronics and wood, especially plywood, a very interesting research area $[2,3]$.

Passive RFID (radio-frequency identification) technology provides automatic identification and tracking of products achieved with battery-free remotely addressable electronic tags composed of an antenna and an integrated circuit (IC) on a substrate. Electromagnetic waves are used by an RFID reader and an RFID tag to communicate with each other. Furthermore, the electromagnetic waves sent by the reader are used to provide operating power for passive RFID tags as they have no power supply of their own. The use of propagating electromagnetic waves in the UHF (ultra high frequency) frequency range for powering and communicating with the passive tags enables rapid interrogation of a large quantity of tags through various media. Unlike barcodes, the IC-enabled tags allow the data stored in them to be updated or read wirelessly at any time. Thanks to the energy efficient mechanism of digitally modulated scattering utilized in the wireless communication, the tags can be read from a distance of several meters $[4,5]$. This makes the passive tags favourable to be used for energy-autonomous wireless sensing platforms, for example, as strain, temperature, and humidity sensors that exhibit low complexity and cost [6-9]. It is possible to establish maintenance-free embeddable sensor components into different kinds of structures without the need for external sensors or on-board electronics, by using a passive UHF RFID tag antennas as the sensing element. Antenna-based sensing provides integration of sensing capabilities in passive RFID tags with a minimal increase in the overall complexity and power consumption of the tag.

One of the most interesting sensor types for passive RFID systems is a humidity sensor, which is due to the great number of materials reacting to humidity-level variations. In addition, 
the information about possible existing humidity or knowing the humidity level is essential in various application areas, including the construction industry, warehousing, and transportation. Previously, humidity sensor prototypes have been developed for UHF RFID systems [8, 10-12] by using traditional photolithography, as well as inkjet and screen printing.

The passive humidity sensor tag, which is presented in this paper, is fabricated directly on plywood substrate by using brush-painting and photonic sintering of cost-effective silver ink. The sensor tag is still at a prototyping stage but the tag is intended to be used for structural humidity monitoring, for example, inside wooden floors and walls, or to sense humidity conditions during transportation. The sensor tag can be used to quickly detect increased humidity level, thus dramatically reducing the amount of additional damage caused by continued humidity exposure. The sensor tag is fully passive, does not need any maintenance procedures, and can be permanently enclosed inside walls, ceilings, floors, and wooden containers for long-term monitoring. In addition, the sensor tag is small in size, allowing fitting inside various structures. This sensor tag also has all the functionalities of an ordinary passive RFID tag, which allows the use of several sensor tags in a small area, as they can be recognized using their unique identification codes. The tags can also be used for automatic identification and supply chain control of the wooden products.

The work presented here is organized as follows: after Introduction, Section 2 introduces the characteristics of used birch plywood. Section 3 introduces our tag design, the used brush-painting and sintering methods, and presents the tag fabrication with the optimized fabrication parameters. The wireless tag measurements and humidity absorption tests are introduced in Section 4. Section 5 presents the results and Section 6 summarizes the conclusions of this study.

\section{Characteristics of Birch Plywood}

Plywood is characterised by its high planar shear strength and impact resistance, excellent surface hardness, wear resistance, and creep resistance. Other good characteristics of birch plywood include being flexible and bendy, being strong and durable, easy working properties, good gluing properties, being ecological and biodegradable, and not to forget the beauty of its surface [13]. All these properties make birch much used and loved material, for example, in building and furniture industries.

Plywood has excellent dimensional stability under heat. In practice, the thermal deformation of plywood is so small that it can generally be disregarded. Standard Finnish plywood and most coated plywood products are suitable for use at temperatures of $100^{\circ} \mathrm{C}$ and many up to $120^{\circ} \mathrm{C}$. Plywood endures cold even better than heat and can be used at sustained temperatures as low as $-200^{\circ} \mathrm{C}$. Although plywood burns, it can have better fire resistance than many materials which do not burn. The temperature at which plywood will ignite when exposed to a naked flame is about $270^{\circ} \mathrm{C}$ and to cause spontaneous combustion, a temperature of over $400^{\circ} \mathrm{C}$ is needed [13]. Thus, the temperature area of plywood is very suitable for the fabrication methods used in this study.
Like all other wood-based materials, plywood is a hygroscopic product and exhibits viscoelastic mechanical behavior. An increase in moisture content will result in a decrease in the strength, modulus of elasticity, and shear modulus values. Thus, also for these reasons, it is necessary to take the moisture conditions into consideration when using plywood.

\section{Fabrication of the Tags}

Brush-painting is a versatile but simple and fast additive manufacturing method. The method not only reduces the process-steps of RFID tag manufacturing, but also minimizes the need of conductive ink material, as the material is dispensed directly to the brush and from the brush directly to the antenna area in the substrate. By brush-painting RFID tags directly on plywood, we can manufacture very thin tags through eliminating the need for additional substrate material. The thickest part of the tag in this case is the IC, which determines the scale of the thickness of the tag. In our case the thickness of the IC is $120 \mu \mathrm{m}$ [14], but the use of even thinner ICs, for example, $75 \mu \mathrm{m}$, is possible, meaning that embedding the tags inside versatile products is convenient. In addition, when the tags are embedded as a part of the wooden product, they will be almost impossible to remove from the product without breaking it, as the wooden item itself acts as the substrate of the tag.

Brush-painting has been previously successfully used for fabrication of tag antennas on fabric substrate with silver nanoparticle ink [15], and on wood substrate with silver and copper nanoparticle inks [16]. In this study, cost-effective screen printable silver ink (Metalon HPS-021LV silver flake ink [17]) was used. The tag antennas were brush-painted through a stencil ( $50 \mu \mathrm{m}$ thick polyimide film) on plywood substrate, by using only one layer of ink. A tag antenna showed in Figure 1(a) was utilized as the antenna geometry. The wood substrate, presented in Figure 1(b), used in this study was $4 \mathrm{~mm}$ thick birch plywood.

Efficient and low-cost manufacturing is more and more important, as a huge amount of RFID components is needed for future IoT applications. These requirements mean that the long sintering times needed in heat sintering are not acceptable. Flash lamp sintering is a photonic sintering method that in ambient conditions uses very short light pulses to heat the ink to a high enough temperature within few micro- or milliseconds. Such transient heating minimizes the damage to heat sensitive substrates. Photonic sintering reduces the sintering times significantly, compared to the widely used heat sintering, which can take tens of minutes. The photonic sintering in this study was done using Xenon Sinteron 2010$\mathrm{L}$ system. The sintering system parameters are lamp voltage, flash pulse duration, and number of flash pulses. The lamp voltage can be adjusted between $1800 \mathrm{~V}$ and $3000 \mathrm{~V}$, in $50 \mathrm{~V}$ increments. The pulse duration can be adjusted and the time between pulses can also be chosen. In order to find the optimized sintering parameters, the resistances of fabricated antennas were measured after sintering, using Fluke 111 True RMS multimeter, and by placing the measurement probes on the corners of the antenna pattern (Diagonal 1: upper left and lower right corners, Diagonal 2: upper right and lower left 


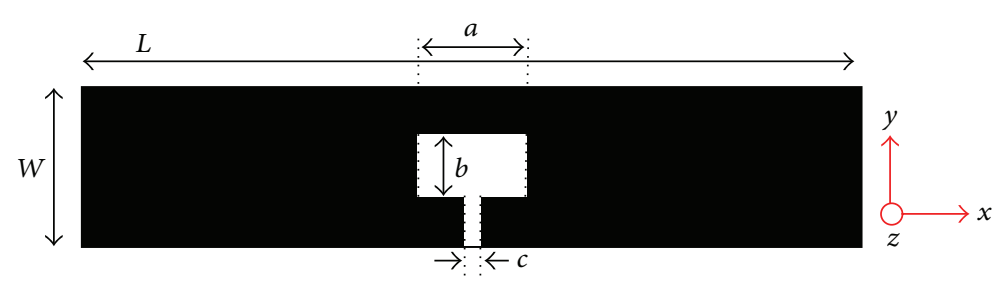

$$
\begin{array}{ll}
\text { Geometrical parameters } & (\mathrm{mm}) \\
L=100 & b=8.125 \\
W=20 & c=2 \\
a=14.3 &
\end{array}
$$

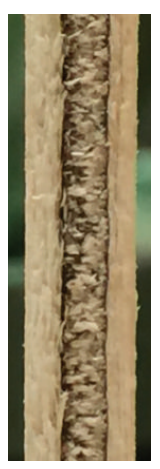

(b)

FIGURE 1: Studied tag antenna geometry (a) and cross section of the used plywood material (b).

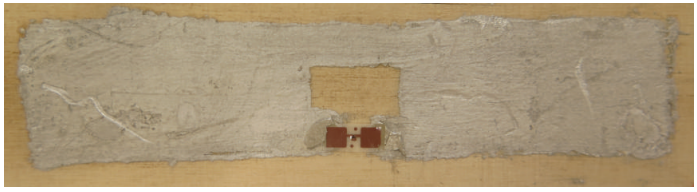

(a)

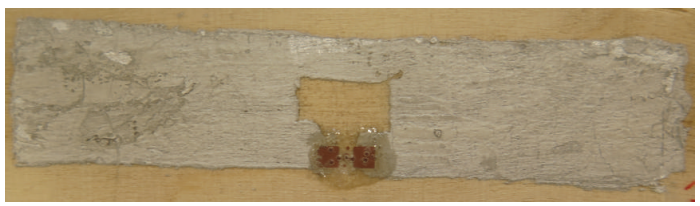

(b)

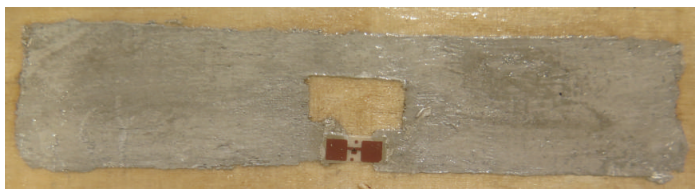

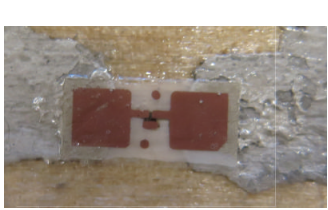
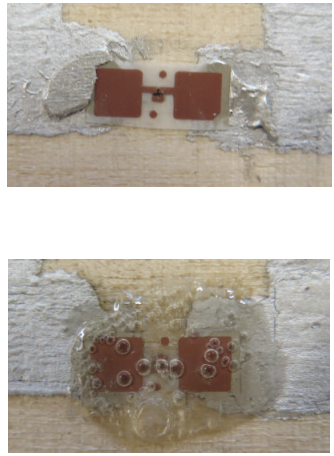

(c)

Figure 2: Noncoated tag and a close-up of the IC-area (a), IC-coated tag and a close-up of the IC-area (b), and all-coated tag and a close-up of the IC-area (c).

TABLE 1: Sintering parameters and measured resistances for antennas on plywood.

\begin{tabular}{lccc}
\hline Voltage $(\mathrm{V})$ & Time $(\mu \mathrm{s})$ & Diagonal $1(\Omega)$ & Diagonal $2(\Omega)$ \\
\hline 2500 & $2500 \times 2$ & 5.8 & 5.3 \\
2500 & $3000 \times 2$ & 4.2 & 3.9 \\
3000 & $3000 \times 2$ & 2.3 & 2.8 \\
\hline
\end{tabular}

corners). The used sintering parameters and the measured resistances for the best three photonically sintered antennas can be seen in Table 1. Based on this preliminary study, the chosen sintering parameters were $3000 \mathrm{~V}$ and $3000 \mu$ s, with two flash pulses.

The tag IC utilized in this experiment was NXP UCODE G2iL series IC [14], which has a low wake-up power of $15.8 \mu \mathrm{W}(-18 \mathrm{dBm})$. The manufacturer had mounted the chip on a fixture with two $3 \times 3 \mathrm{~mm}^{2}$ copper pads, which we connected to the antenna terminals using conductive epoxy (Circuit Works CW2400). 
TABLE 2: Results of moisture absorption: mean change in mass and standard deviation after each testing time.

\begin{tabular}{lccccc}
\hline & Time & $\begin{array}{c}\text { After 100\% RH } \Delta \mathrm{m} \\
(\%) \text { mean }\end{array}$ & $\begin{array}{c}\text { After 100\% RH } \Delta \mathrm{m} \\
\text { (\%) st. dev. }\end{array}$ & $\begin{array}{c}\text { After 9 days } \Delta \mathrm{m} \\
(\%) \text { mean }\end{array}$ & $\begin{array}{c}\text { After } 9 \text { days } \Delta \mathrm{m} \\
(\%) \text { st. dev. }\end{array}$ \\
\hline \multirow{2}{*}{ Noncoated } & $5 \mathrm{~min}$ & 20.51 & 0 & 0.39 & 0 \\
& $1 \mathrm{~h}$ & 46.08 & 0 & 0.44 & 0 \\
\hline \multirow{2}{*}{ IC-coated } & $5 \mathrm{~min}$ & 22.66 & 0.08 & 0.46 & 0.03 \\
& $1 \mathrm{~h}$ & 37.56 & 1.74 & 0.47 & 0.13 \\
\hline \multirow{2}{*}{ All-coated } & $5 \mathrm{~min}$ & 14.90 & 6.60 & 0.47 & 0.13 \\
& $1 \mathrm{~h}$ & 31.22 & 5.92 & & 0.05 \\
\hline
\end{tabular}

tested before and after humidity exposure, after 9 days from humidity exposure, and finally behind and under wood layer.

4.1. Measurements of Moisture Absorption. The moisture absorption test measured the moisture absorption in $100 \%$ relative humidity $(\mathrm{RH})$. Before testing, the samples were kept in office conditions for 9 days and then weighted. The testing times were 5 minutes and 1 hour (also shown in Table 2). During testing, noncoated tags, tags with a coated IC, and all-coated tags were weighed after each submission time, and the mean change in weight was calculated. All samples were measured again after drying 9 days in office conditions. The accuracy of weight measurement was $0.0001 \mathrm{~g}$ and 15 samples were measured.

4.2. Wireless Performance before and after Moisture Absorption. The performance of the brush-painted sensor tags was analyzed after tag manufacturing, after coating, and twice after the moisture absorption test: immediately after the $100 \% \mathrm{RH}$ test and after 9 days in office conditions. The measurements were based on the measured threshold power $\left(P_{\text {th }}\right)$, which is the minimum output power of an RFID reader to activate the tag under test from a given distance. It can be measured using RFID readers and testers with adjustable output power. In this work, we have used Voyantic Tagformance measurement system [18] to conduct the measurement through a range of frequencies from $800 \mathrm{MHz}$ to $1000 \mathrm{MHz}$. Because the measured threshold power depends on the measurement site and hardware, we used the attainable free-space read range of the tag $\left(d_{\text {tag }}\right)$ derived from $P_{\text {th }}$ to provide universal tag characterization. As detailed in [19], we can estimate $d_{\text {tag }}$ based on the measured threshold power of the tag under test and a system reference tag as

$$
d_{\mathrm{tag}}=\frac{\lambda}{4 \pi} \sqrt{\frac{\mathrm{EIRP}}{\Lambda} \frac{P_{\mathrm{th}^{*}}}{P_{\mathrm{th}}}},
$$

where $\Lambda$ is a parameter (unit: watts) describing the sensitivity of the reference tag of the measurement system and $P_{\text {th }^{*}}$ is the measured threshold power of the reference tag. In this paper, we report all the read range results under the European RFID emission regulation: EIRP $=3.28 \mathrm{~W}$, in the direction of the positive $y$-axis in Figure 1. In general, the $y z$-plane is the omnidirectional plane of the dipole antenna where the read range is approximately equal in all directions. In all measurements, the tag was aligned for polarization matching with a linearly polarized reader antenna. Based on the calibration data provided by the manufacturer of the measurement system, we have estimated that the maximum variability in $d_{\text {tag }}$ due to variability in the system reference tag $(\Lambda)$ and the output power meter of the reader $\left(P_{\text {th }}\right.$ and $\left.P_{\mathrm{th}^{*}}\right)$ is less than $5 \%$ throughout the studied frequency range.

The response from the passive tag is affected by the prevailing circumstances and surrounding materials. In case of a passive humidity sensor tag on plywood, the response of the tag as a function of increased humidity is measured. The increased moisture will change the permittivity of the wooden substrate and thus change the impedance of the antenna, which will create a mismatch between the tag antenna and the IC. The increased moisture will also increase the losses in the wooden substrate, degrading the overall tag performance. That is, the humidity will cause a degradation of the tag performance, enabling the antenna-based sensing of humidity.

\section{Results}

5.1. Results of Moisture Absorption in 100\% RH. The results of the moisture absorption measurements can be seen in Table 2. According to these results, the mean change in mass was between 15\% (all-coated) and 23\% (IC-coated) already after 5 minutes in $100 \% \mathrm{RH}$, which means that the plywood material quickly absorbs a lot of moisture. After $1 \mathrm{~h}$ in $100 \%$ $\mathrm{RH}$, the mean change in mass was between $31 \%$ (all-coated) and $46 \%$ (noncoated), which means that about half of the mass increase occurs during the first 5 minutes, and the degree of moisture saturation is most probably near $100 \%$ after $1 \mathrm{~h}$. However, even though the plywood absorbs quickly a lot of moisture, it also dries after removal from moist conditions. In the mass measurements after 9 days, it can be seen that only a very small amount of moisture is still absorbed. These changes in mass after 9 days, compared to the initial measurements, are so small that they could also be due to changes in the moisture content of office conditions. The next step of this research is to conduct exact moisture level measurements that will be used in addition to these prototype stage moisture absorption measurements.

5.2. Results of Wireless Measurements. The read range results for noncoated, IC-coated, and all-coated tags (after 9 days in office conditions, after adding the possible protective coating, 


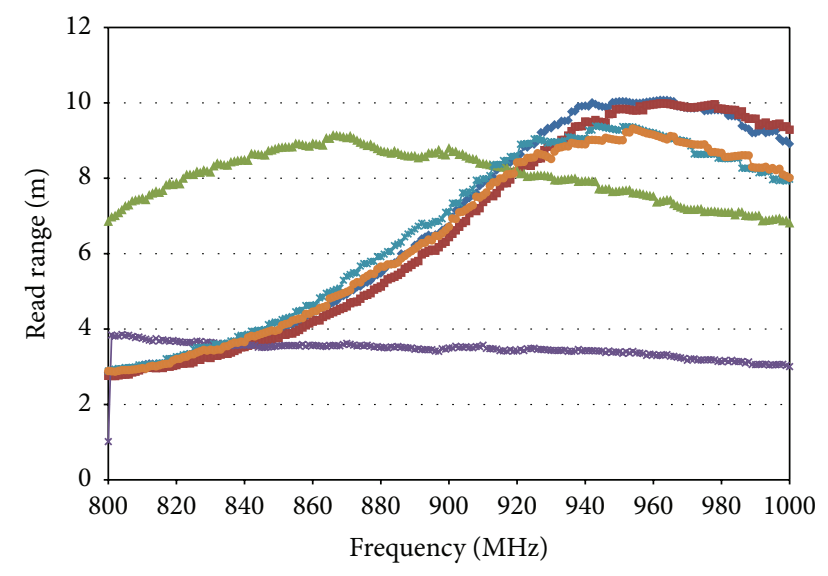

$\longrightarrow$ Noncoated, initial (sample 1)

$\longrightarrow$ Noncoated, initial (sample 2)

— Noncoated, $5 \mathrm{~min}$ (sample 1)

* Noncoated, $1 \mathrm{~h}$ (sample 2)

- Noncoated, $5 \mathrm{~min}$, after 9 days (sample 1)

- Noncoated, $1 \mathrm{~h}$, after 9 days (sample 2)

FIGURE 3: Measurement results for noncoated sensor tags.

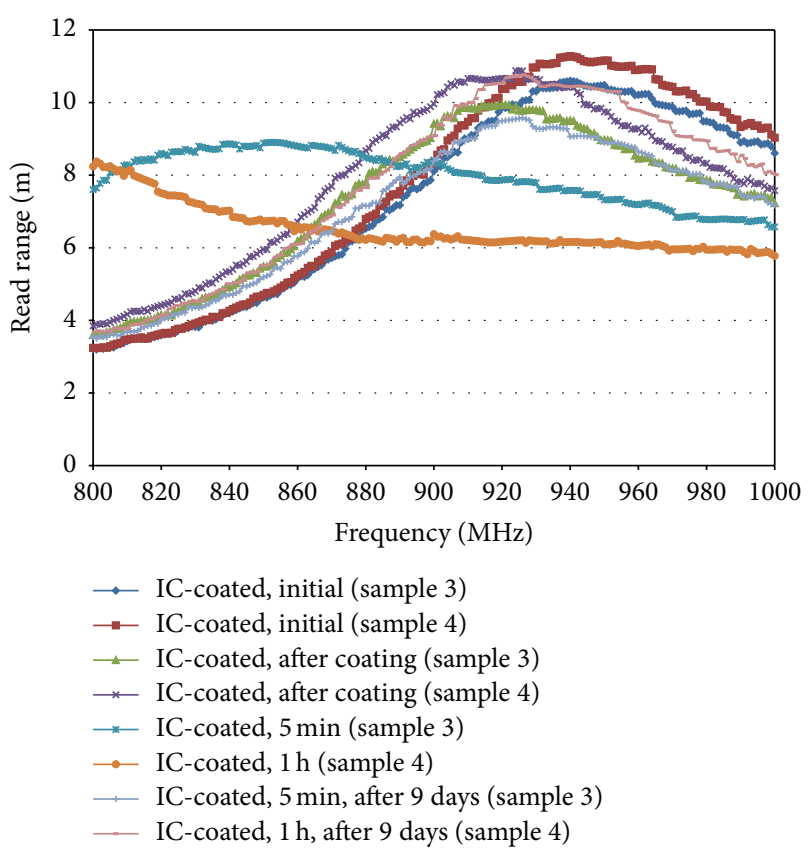

FiguRE 4: Measurement results for IC-coated sensor tags.

immediately after $100 \%$ RH testing, and after 9 days in office conditions) are shown in Figures 3-5, respectively.

As shown, these tags initially achieved peak read ranges of $10-11$ meters in $940-970 \mathrm{MHz}$, which is more than sufficient for embedded humidity sensor applications. The achieved results are in line with the earlier results realized with the same antenna geometry: in [3], brush-painted silver nanoparticle RFID tags with the same antenna geometry on polyimide substrate showed peak read ranges of over 9 meters in the frequency range of $940-970 \mathrm{MHz}$ (with photonic sintering)

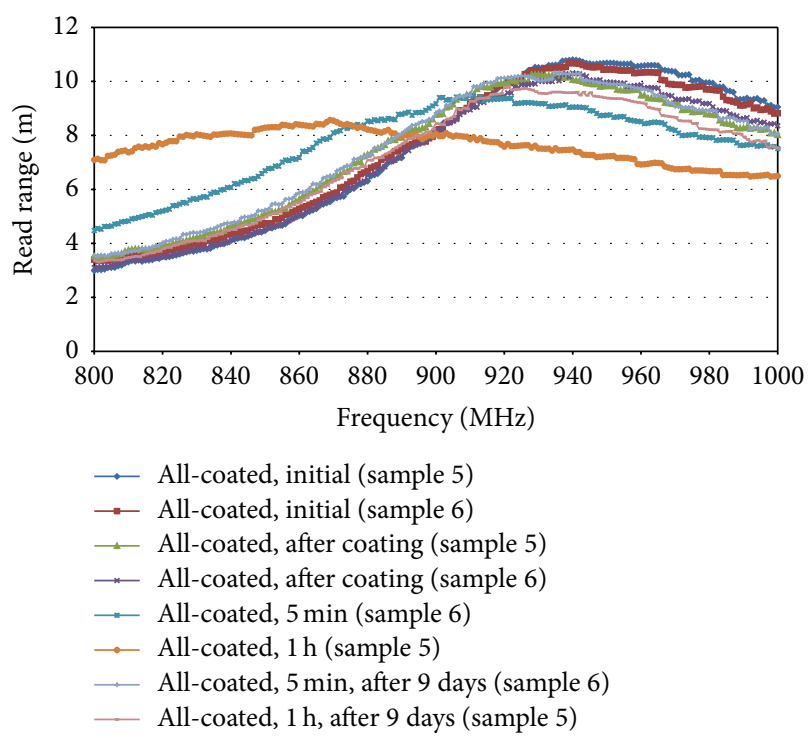

FIGURE 5: Measurement results for all-coated sensor tags.

and over 8 meters in the frequency range of $940-970 \mathrm{MHz}$ (with heat sintering). Also, in [16], read ranges of about 5 and 3 meters throughout the global UHF RFID band were measured for brush-painted silver and copper nanoparticle RFID tags, respectively, with the same antenna geometry on wood substrate. For these tags, there was no clear peak read range at any frequency. A wooden surface was found to be a challenging surface for brush-painted nanoparticle, inkjetprintable inks, due to its porosity and high surface roughness, as the ink droplets were easily absorbed by the substrate [16]. This problem can be avoided by using screen printing inks, such as the ink in this study. However, if antenna geometries with really narrow and precise conductors are needed, use of inkjet-printable nanoparticle inks as sensor antenna could be studied with an additional substrate material on top of the plywood.

The measurement results presented in Figures 3-5 show that after being exposed to $100 \% \mathrm{RH}$, the performance of the tags changed significantly. The most dramatic change can be seen in Figure 3 for the noncoated tags. The maximum read range decreased from about 10 meters to below 4 meters, and no peak in read range in any frequency could be seen. The read ranges of the noncoated tags changed immediately after 5 minutes exposure to $100 \% \mathrm{RH}$, as can be seen in Figure 3, but the change was not as radical as after 1-hour exposure time. After 9 days in office conditions, the performance of the tags returned back to normal, as the tags had dried. These results of wireless read range measurement are supported by the earlier mass change measurement results.

The 100\% RH exposure also affected the read ranges of the IC-coated tags after 5 minutes of humidity exposure, and even more after 1 hour in $100 \% \mathrm{RH}$. The performance of the IC-coated tags is very similar to the noncoated tags. After 1 hour in high humidity, the performance of the IC-coated tags seems to be better than the noncoated tags, which is probably due to the effects of moisture on the noncoated IC in case of the noncoated tags. The all-coated tags endured $100 \% \mathrm{RH}$ 
exposure quite well: after 1 hour in $100 \% \mathrm{RH}$, the peak read range was 3 meters shorter than before any humidity testing. However, the peak frequency changed to significantly lower frequency. Altogether, the all-coating of tags shields the tags very well against $100 \% \mathrm{RH}$, and the reliability of the tags in normal RFID identification applications can be significantly increased by coating. After 9 days in office conditions, also the performance of the IC-coated and all-coated tags returned back to normal, whose results are also supported by the mass change measurement results.

In measurements of the IC-coated and all-coated tags, it could be seen that the coating of the IC-area affects the read range up to some extent. The peak read ranges of these tags were slightly shorter after coating than before coating. This change is in the range of about 1 meter and thus acceptable. The read ranges are more than sufficient to the intended applications even after the coating process.

According to our results, the moisture content of the substrate affected the passive UHF RFID tag performance on plywood substrate. The moisture did not prevent the tags from working, although the tag antenna impedance and the ohmic losses were affected by the moisture. These first results are very encouraging to further investigate the moisture sensing based on brush-painted passive UHF RFID tags on plywood substrate. The relation of the humidity exposure time and the change in the read range, especially in case of the noncoated tags, indicate that the tags could be used as humidity sensors in addition to normal RFID identification purposes. If the tags are intended to be used only as normal RFID identification tags in a high humidity environment, the all-coated tag should be chosen, because of the remarkable reliability increase against humidity. Based on our results, adding the protective coating on only the IC-area does not give any significant benefit either in use as a humidity sensor or in normal use as an identification tag: the reliability of the all-coated tags is significantly better and the sensor sensitivity to humidity is greater without any coating. However, a longerterm exposure to high humidity must first be studied.

Next, the tags were measured behind a $4 \mathrm{~cm}$ thick wooden wall and under a $4 \mathrm{~cm}$ thick wooden layer, and the measurement results can be seen in Figures 6 and 7, respectively. Based on our measurements, the wooden material on top of the tag or in front of the tag had a decreasing effect on the read range, and the peak frequency changed to lower frequency. In addition, the peak frequency is not as clear as without a wood layer. However, all tags still achieved read ranges of 6-9 meters throughout the global UHF RFID band. According to these results, the fabricated tags are suitable to be embedded into various wooden products and into wooden structures. It should be noted, however, that all of the measurements were performed in situations where there were no adjacent tags in close proximity. In practical applications, several tags may lay in close proximity. As tags are brought closer to one another, their operation characteristics can alter significantly $[20,21]$. If the mutual coupling effect is not taken into account when placing the embedded tags, the readability of the tags could be degraded.

As copper-based conductive inks have recently provided more cost-effective alternatives to commonly used silver inks,

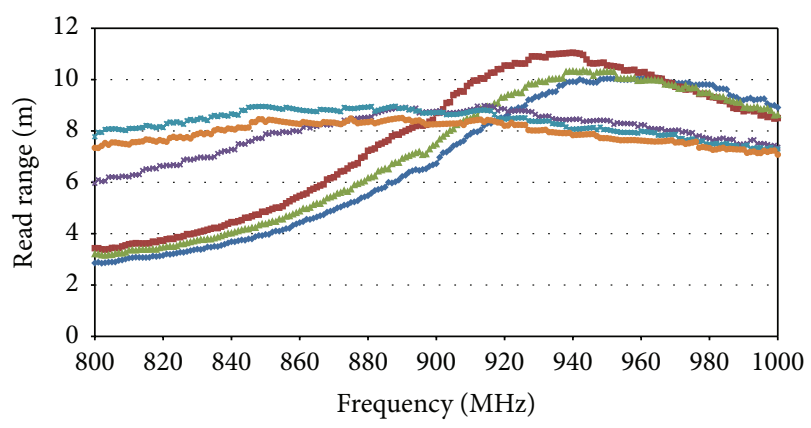

$$
\begin{array}{ll}
\longrightarrow \text { Noncoated, initial } & - \text { Noncoated, behind } \\
\longrightarrow \text { IC-coated, initial } & - \text { IC-coated, behind } \\
\longrightarrow \text { All-coated, initial } & - \text { All-coated, behind }
\end{array}
$$

FIgURE 6: Measurement results behind $4 \mathrm{~cm}$ thick wooden wall.

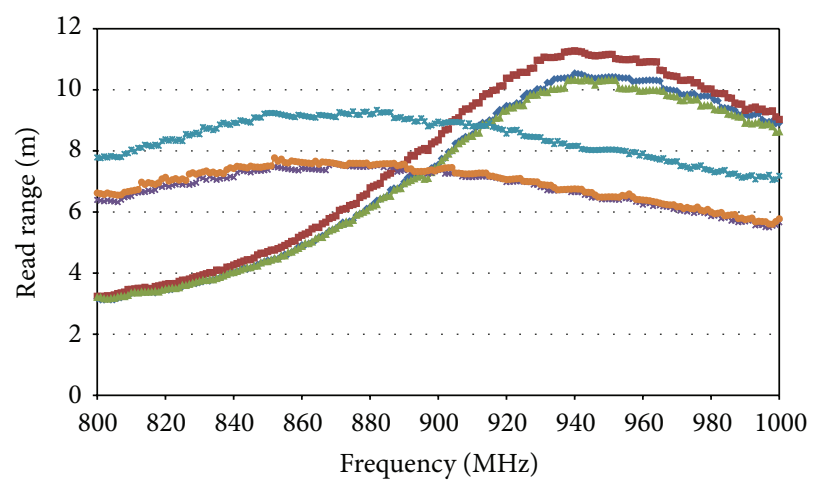

$\begin{array}{ll}\longrightarrow \text { Noncoated, initial } & \longrightarrow \text { Noncoated, under } \\ \longrightarrow \text { IC-coated, initial } & - \text { IC-coated, under } \\ \longrightarrow \text { All-coated, initial } & \rightarrow \text { All-coated, under }\end{array}$

Figure 7: Measurement results under $4 \mathrm{~cm}$ thick wooden layer.

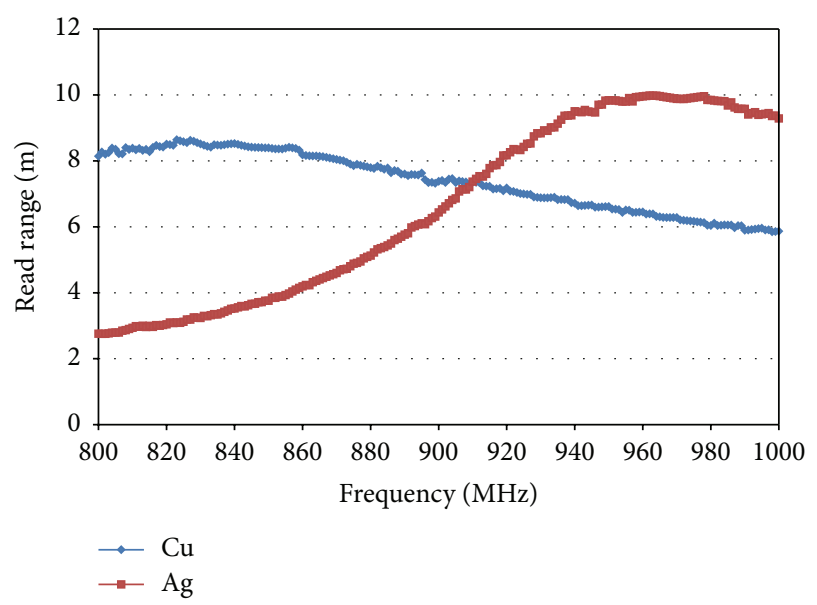

FIGURE 8: Measurement results for copper and silver tags.

the next step in our research will be to study the use of copper-based tag components as humidity sensors. The first prototype copper tag on plywood substrate was fabricated from Metalon ICI-021 copper oxide ink [22], by using brushpainting and photonic sintering. The read range measurement results are shown in Figure 8 and the fabricated tag is 


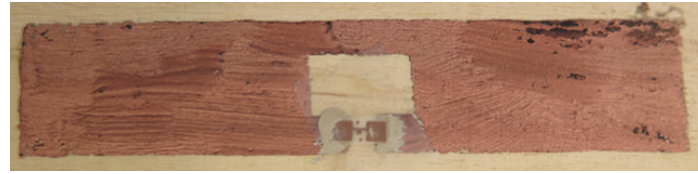

FIGURE 9: Fabricated copper tag.

presented in Figure 9. According to our measurement results, the copper tags achieved peak ranges of about 8 meters, and read ranges of over 6 meters throughout the global UHF RFID band. Thus, these copper tags on a wood substrate provide a great potential for future wireless applications. The next step is to study their use as humidity sensors.

\section{Conclusions}

In this paper, embedding of fully passive RFID-based humidity sensors into plywood structures was studied. The sensor tag antennas were brush-painted on plywood substrate with silver ink and photonic sintering was used as the sintering method. These fabrication methods enable fast and costeffective manufacturing of sensor tags. The sensor performance was strongly dependent on the amount of moisture the tags were exposed to. According to our results, the fabricated RFID-based humidity sensor components have a great potential to be utilized in humidity sensing applications but also in automatic identification and supply chain control of various wooden products, especially in the packaging and construction industry. To the best of our knowledge, this is the first demonstration of brush-painted humidity sensor tags. In the next stage, the sensors will be optimized for the readout with an off-the-shelf RFID reader operating in a fixed regionally regulated frequency band. Also the use of more cost-effective copper-based inks will be further studied.

\section{Conflict of Interests}

None of the authors has any conflict of interests.

\section{References}

[1] M. M. Tentzeris, L. Yang, A. Rida, A. Traille, R. Vyas, and T. Wu, "Inkjet-printed RFID tags on paper-based substrates for UHF 'cognitive intelligence' applications,' in Proceedings of the 18th International Symposium on Personal, Indoor and Mobile Radio Communications (PIMRC '07), pp. 1-4, IEEE, Athens, Ga, USA, September 2007.

[2] J. Virtanen, J. Virkki, L. Sydänheimo, M. Tentzeris, and L. Ukkonen, "Automated identification of plywood using embedded inkjet-printed passive UHF RFID tags," IEEE Transactions on Automation Science and Engineering, vol. 10, no. 3, pp. 796-806, 2013.

[3] E. Sipilä, J. Virkki, L. Sydänheimo, and L. Ukkonen, "Effect of sintering method on the read range of brush-painted silver nanoparticle UHF RFID tags on wood and polyimide substrates," in Proceedings of the IEEE RFID Technology and Applications Conference (RFID-TA '14), pp. 219-222, Tampere, Finland, September 2014.
[4] P. V. Nikitin and K. V. S. Rao, "Antennas and propagation in UHF RFID systems," in Proceedings of the IEEE International Conference on RFID, pp. 277-288, IEEE, Las Vegas, Nev, USA, April 2008.

[5] D. Dobkin, The RF in RFID: Passive UHF RFID in Practice, Newnes, Elsevier, 2008.

[6] G. Marrocco, "Pervasive electromagnetics: sensing paradigms by passive RFID technology," IEEE Wireless Communications, vol. 17 , no. 6 , pp. $10-17,2010$.

[7] F. Long, X. D. Zhang, T. Björninen et al., "Implementation and wireless readout of passive UHF RFID strain sensor tags based on electro-textile antennas," in Proceedings of the 9th European Conference on Antennas and Propagation (EuCAP '15), pp. 1-5, IEEE, Lisbon, Portugal, April 2015.

[8] J. Virtanen, L. Ukkonen, T. Björninen, and L. Sydänheimo, "Printed humidity sensor for passive UHF RFID systems," in Proceedings of the IEEE Sensors Applications Symposium (SAS '10), pp. 269-272, Limerick, Ireland, February 2010.

[9] S. Merilampi, T. Björninen, L. Ukkonen, P. Ruuskanen, and L. Sydänheimo, "Embedded wireless strain sensors based on printed RFID tag," Sensor Review, vol. 31, no. 1, pp. 32-40, 2011.

[10] K. Chang, Y. H. Kim, Y. J. Kim, and Y. J. Yoon, "Functional antenna integrated with relative humidity sensor using synthesised polyimide for passive RFID sensing," Electronics Letters, vol. 43, no. 5, pp. 7-8, 2007.

[11] A. Oprea, N. Bârsan, U. Weimar, M.-L. Bauersfeld, D. Ebling, and J. Wöllenstein, "Capacitive humidity sensors on flexible RFID labels," Sensors and Actuators B: Chemical, vol. 132, no. 2, pp. 404-410, 2008.

[12] Y. Jia, M. Heiss, Q. Fu, and N. A. Gay, "A prototype RFID humidity sensor for built environment monitoring," in Proceedings of the International Workshop on Education Technology and Training and the International Workshop on Geoscience and Remote Sensing (ETT-GRS '08), vol. 2, pp. 496-499, IEEE, Shanghai, China, December 2008.

[13] Forest Products Laboratory, "Wood handbook-wood as an engineering material," General Technical Report FPL-GTR-113, U.S. Department of Agriculture, Forest Service, Forest Products Laboratory, Madison, Wis, USA, 2001.

[14] NXP UCODE G2iL IC, June 2015, http://www.nxp.com/documents/data_sheet/SL3S1203_1213.pdf.

[15] J. Virkki, T. Björninen, L. Sydänheimo, and L. Ukkonen, “Brushpainted silver nanoparticle UHF RFID tags on fabric substrates," in Proceedings of the Progress in Electromagnetics Research Symposium (PIERS '14), pp. 2106-2110, Guangzhou, China, August 2014.

[16] E. Sipilä, J. Virkki, L. Sydänheimo, and L. Ukkonen, "Experimental study on brush-painted metallic nanoparticle UHF RFID tags on wood substrates," IEEE Antennas and Wireless Propagation Letters, vol. 14, pp. 301-304, 2015.

[17] Metalon HPS-021LV Silver Screen Ink, May 2015, http://store.novacentrix.com/v/vspfiles/assets/images/metalon $\% 20 \mathrm{hps}-021 \mathrm{lv}$ 2230.1.pdf.

[18] Voyantic, Espoo, Finland, May 2015, http://www.voyantic.com/.

[19] J. Virkki, T. Björninen, S. Merilampi, L. Sydänheimo, and L. Ukkonen, "The effects of recurrent stretching on the performance of electro-textile and screen-printed ultra-high-frequency radio-frequency identification tags," Textile Research Journal, vol. 85, no. 3, pp. 294-301, 2015.

[20] H.-J. Li, H.-H. Lin, and H.-H. Wu, "Effect of antenna mutual coupling on the UHF passive RFID tag detection," in Proceedings of the IEEE International Symposium on Antennas and 
Propagation and USNC/URSI National Radio Science Meeting (APSURSI '08), San Diego, Calif, USA, July 2008.

[21] F. Lu, X. Chen, and T. T. Ye, "Performance analysis of stacked RFID tags," in Proceedings of the IEEE International Conference on RFID, pp. 330-337, IEEE, Orlando, Fla, USA, April 2009.

[22] Metalon ICI-021 Copper Oxide Screen Ink, May 2015, https:// store.novacentrix.com/v/vspfiles/assets/images/metalon\%20ici021\%202229.1.pdf. 


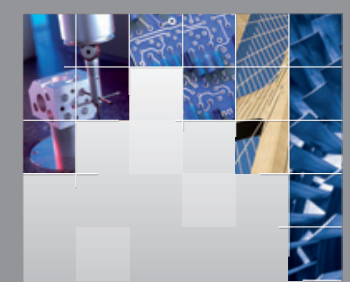

\section{Enfincering}
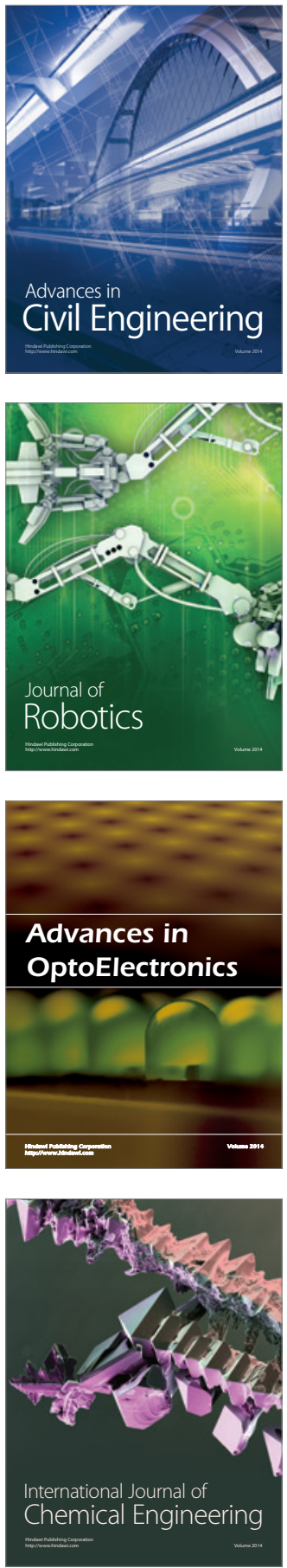

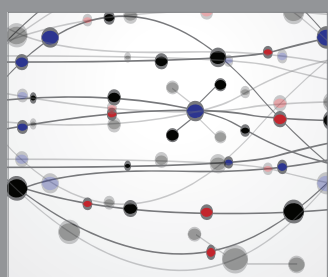

The Scientific World Journal

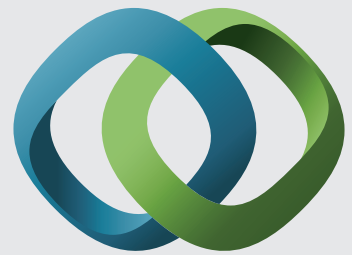

\section{Hindawi}

Submit your manuscripts at

http://www.hindawi.com
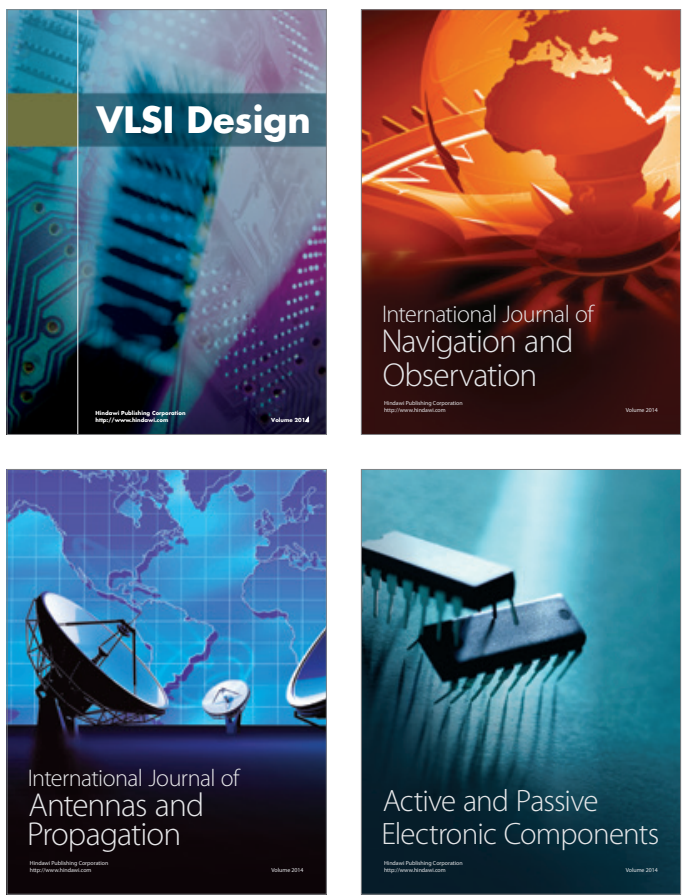
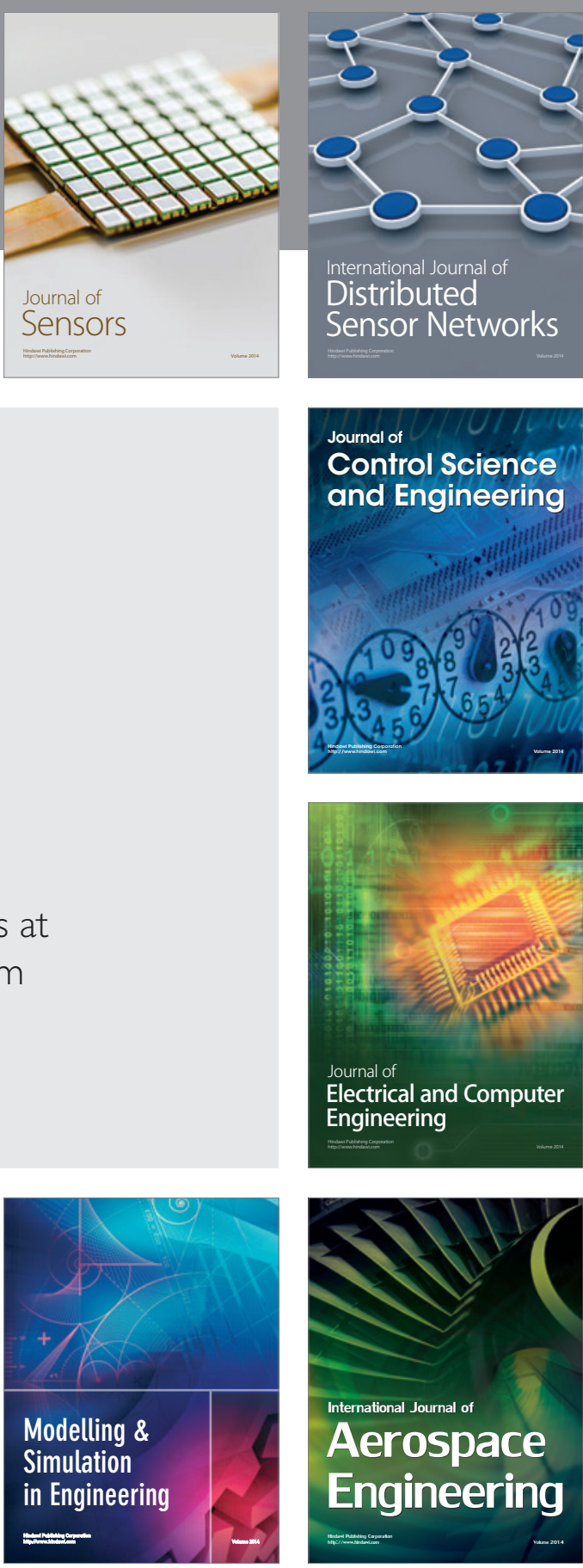

International Journal of

Distributed

Sensor Networks

Journal of

Control Science

and Engineering
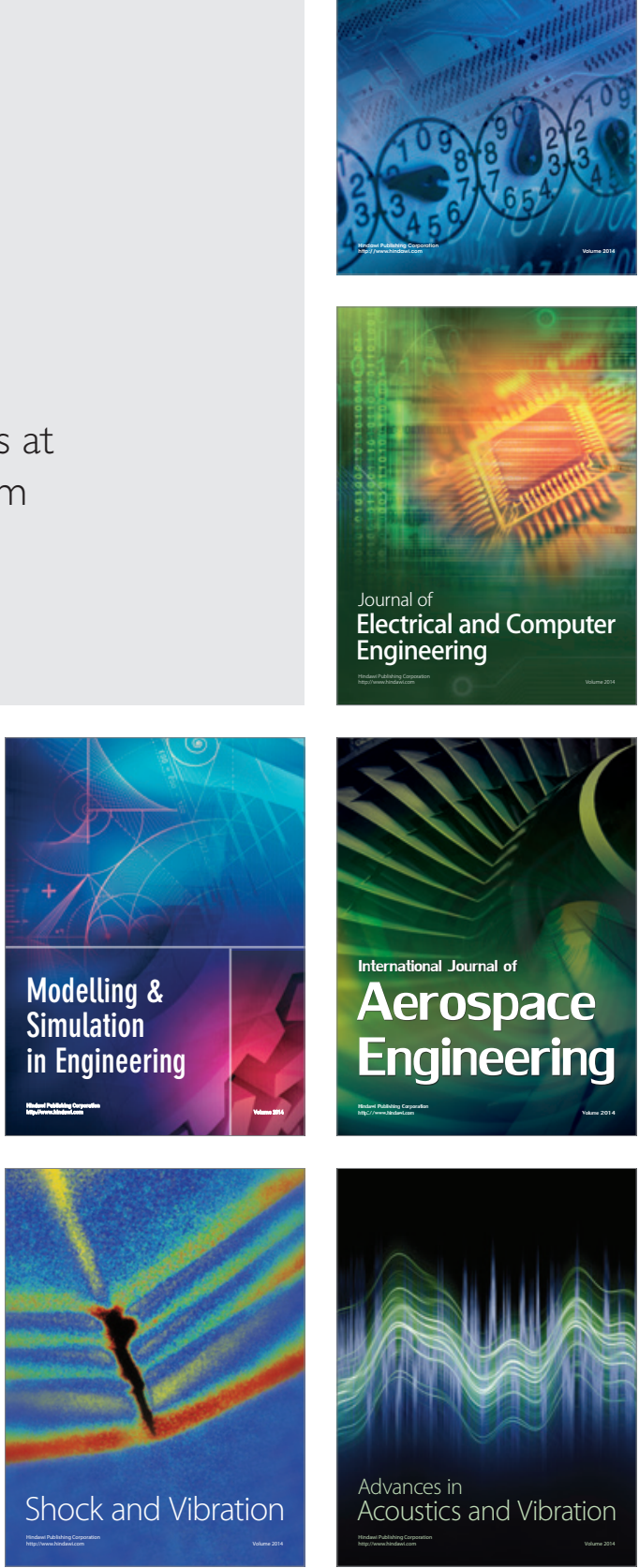